\title{
The first draft genomes of the ant Formica exsecta, and its Wolbachia endosymbiont reveal extensive gene transfer from endosymbiont to host
}

\author{
Kishor Dhaygude ${ }^{1 *} \mathbb{D}$, Abhilash Nair ${ }^{1}$, Helena Johansson ${ }^{1}$, Yannick Wurm² and Liselotte Sundström ${ }^{1,3}$
}

\begin{abstract}
Background: Adapting to changes in the environment is the foundation of species survival, and is usually thought to be a gradual process. However, transposable elements (TEs), epigenetic modifications, and/or genetic material acquired from other organisms by means of horizontal gene transfer (HGTs), can also lead to novel adaptive traits. Social insects form dense societies, which attract and maintain extra- and intracellular accessory inhabitants, which may facilitate gene transfer between species. The wood ant Formica exsecta (Formicidae; Hymenoptera), is a common ant species throughout the Palearctic region. The species is a well-established model for studies of ecological characteristics and evolutionary conflict.
\end{abstract}

Results: In this study, we sequenced and assembled draft genomes for F. exsecta and its endosymbiont Wolbachia. The F. exsecta draft genome is $277.7 \mathrm{Mb}$ long; we identify 13,767 protein coding genes, for which we provide gene ontology and protein domain annotations. This is also the first report of a Wolbachia genome from ants, and provides insights into the phylogenetic position of this endosymbiont. We also identified multiple horizontal gene transfer events (HGTs) from Wolbachia to F. exsecta. Some of these HGTs have also occurred in parallel in multiple other insect genomes, highlighting the extent of HGTs in eukaryotes.

Conclusion: We present the first draft genome of ant F. exsecta, and its endosymbiont Wolbachia (WFex), and show considerable rates of gene transfer from the symbiont to the host. We expect that especially the $F$. exsecta genome will be valuable resource in further exploration of the molecular basis of the evolution of social organization.

Keywords: Formica exsecta, Genome, Endosymbionts, Transposons, Horizontal gene transfer, Wolbachia

\section{Background}

Adapting to changes in the environment is the foundation of species survival, and is usually thought to be a gradual process. Genomic changes, such as single nucleotide substitutions play key roles in adaptive evolution, although few mutations are beneficial. Besides nucleotide substitutions, other structural and regulatory units, such as transposable elements (TEs) and epigenetic modifications, can also act as drivers in adaptation [1-3]. Genetic material can also be acquired from other organisms by means of

\footnotetext{
* Correspondence: kishor.dhaygude@helsinki.fi

${ }^{1}$ Organismal and Evolutionary Biology Research Programme, Faculty of Biological and environmental sciences, University of Helsinki, P.O. Box 65, Fl-00014 Helsinki, Finland

Full list of author information is available at the end of the article
}

horizontal gene transfer (HGTs), and this can also lead to novel adaptive traits $[4,5]$. Both mutations and HGTs can drive rapid genome evolution [6, 7]. Horizontal gene transfers have been reported in many taxa, most commonly from bacteria to animals [7], plants [8, 9], fungi [10-12], but the mechanisms that underpin horizontal gene transfer events, and the mode by which bacterial genetic material is integrated into the eukaryote genome are not well understood.

Many cases of horizontal gene transfer from bacteria to eukaryotes involve intracellular endosymbionts, which are maternally transmitted through oocytes $[13,14]$. The most common examples of endosymbiont to host horizontal gene transfers involve the bacterium Wolbachia, a well described intracellular, maternally inherited gram-negative

(c) The Author(s). 2019 Open Access This article is distributed under the terms of the Creative Commons Attribution 4.0 International License (http://creativecommons.org/licenses/by/4.0/), which permits unrestricted use, distribution, and reproduction in any medium, provided you give appropriate credit to the original author(s) and the source, provide a link to the Creative Commons license, and indicate if changes were made. The Creative Commons Public Domain Dedication waiver (http://creativecommons.org/publicdomain/zero/1.0/) applies to the data made available in this article, unless otherwise stated. 
bacterium known to infect over $60 \%$ of the investigated insect species [15-17]. Wolbachia infection is also prevalent in filarial nematodes, crustaceans, and arachnids [18-20]. Wolbachia- host interactions can be mutualistic or pathogenic [21]. A number of ecdysozoan genomes have been reported to contain chromosomal insertions originating from Wolbachia, including the mosquito Aedes aegypti [22, 23], the longhorn beetle Monochamus alternatus [24], filarial nematodes of the genera Onchocerca, Brugia, and Dirofilaria [20, 25], parasitoid wasps of the genus Nasonia, the fruit fly Drosophila ananassae, the pea aphid Acyrthosiphon pisum [26, 27], and the bean beetle Callosobruchus chinensis [28]. Although most of the transferred DNA is probably nonfunctional in the host genome $[25,28,29]$, some of the transferred genes are functional [22]. The functional HGT events can be categorized into two broad types - one that maintains pre-existing functions in the recipient host, and one that provides the recipient host with new functionality, including altered host nutrition, protection and adaptation to extreme environments [30].

Infection with Wolbachia is widespread in Hymenoptera. Most hymenopteran Wolbachia infections have the cytoplasmic incompatibility phenotype [31], which leads to reproductive incompatibility between infected sperm and uninfected eggs. The ants that have been investigated so far are infected with A-group strains of CI-inducing Wolbachia [32-34]. Wenseleers et al. [35] showed that 25 out of 50 species of ants in Java and $\mathrm{Su}$ matra screened positive for a single A-group strain of Wolbachia. By contrast, a study on a single Swiss population of the ant Formica exsecta, found that all the ants tested were infected with four or five different strains of Wolbachia [32, 36].

The aims of this study are to produce the first genome for the ant genus Formica, to test whether horizontally transferred genetic elements exist in the genome of the ant $F$. exsecta, and to describe the genomic organization of any such elements. The genus Formica is listed by the Global Ant Genome Alliance (GAGA) as one of the high-priority ant taxons to be sequenced [37], owing to its key taxonomic position, and the ecological and behavioral data that are available for the species. We report the first whole genome sequencing of this species, and the draft genome sequence of its associated cytoplasmic Wolbachia endosymbiont ( $w$ Fex). We further report the presence of multiple extensive insertions of $\mathrm{Wol}$ bachia genetic material in the host genome, and compare the HGTs insertions discovered in the assembled draft genome to other genomes, to understand the pattern of HGT events between endosymbiont and host. We analyze in detail the genomic features of $F$. exsecta along with its endosymbiont Wolbachia, and discuss our findings in the light of genome evolution in Wolbachia and its host.

\section{Results \& discussion}

\section{The $F$. exsecta genome}

The Illumina sequencing libraries from DNA extracted from testes of males of a $F$. exsecta colony yielded $>99$ gigabases of Illumina sequence data. The final genome resulting from the assembly of these data was 277.7 megabases $(\mathrm{Mb})$ long, encompassing 14,617 scaffolds (Fig. 1) with a N50 scaffold length of $997.7 \mathrm{~kb}$ (Table 1). The number of scaffolds is higher than the number of chromosomes $(n=26)$ reported for $F$. exsecta [38, 39]. Similarly, the F. exsecta genome assembly is somewhat shorter than genome size estimates obtained by flow cytometry for species in the subfamily Formicinae (range: 296-385 Mb) [40]. These discrepancies are unsurprising given the difficulty of assembling highly repetitive gene content from short sequencing reads [41]. In line with this, the genome assembly length metrics are similar to those of the 23 ant genomes that have been published. The raw data, gapped scaffolds, and annotations underpinning this assembly are deposited on public databases under BioProject PRJNA393850 (accession NPMM00000000).

\section{Quantitative assessment of genome assembly}

Based on scaffold N50 and N75 statistics, contig size, and $\mathrm{GC}$ content, the $F$. exsecta genome assembly is comparable in quality and completeness to other sequenced ant genomes (Additional file 1: Table S1). All the 248 CEGMA eukaryotic core genes were found, and 241 of these genes were complete in length. Similarly, $98.5 \%$ of 1634 BUSCO Insecta genes were complete in the genome (Table 2). These results held with other BUSCO analysis levels including Eukaryota, Arthropoda, and Hymenoptera, with low duplication levels (2.2 to $5.3 \%$ ), and a few missing genes (0.6 to $1.27 \%$; Table 2 ). Such discrepancies can be due to technical artifacts such as sequencing biases or assembly difficulties, as well as to true differences between our $F$. exsecta sample and the BUSCO and CEGMA datasets. To further evaluate genome completeness, we compared the independently generated $F$. exsecta transcriptome [42] to the genome reported here. More than $98.75 \%$ of the 10.999 assembled ESTs mapped unambiguously to the genome (BLASTn $\mathrm{E}<10^{-50}$ ). Together, these analyses show that the genome assembly has high completeness.

\section{Gene content in the $F$. exsecta genome}

We identified 13,637 protein coding genes by combining ab initio, EST-based, and sequence similarity based gene predictions methods. The GC content was higher in exons (41.6\%) than in introns (30.6\%), a pattern similar to that reported in the honey bee, Apis mellifera, and the fire ant, Solenopsis invicta $[43,44]$. Despite this, as in other ant genomes [37, 45], the overall GC content in genes (35.1\%) was similar to the rest of the genome (36.0\%). 


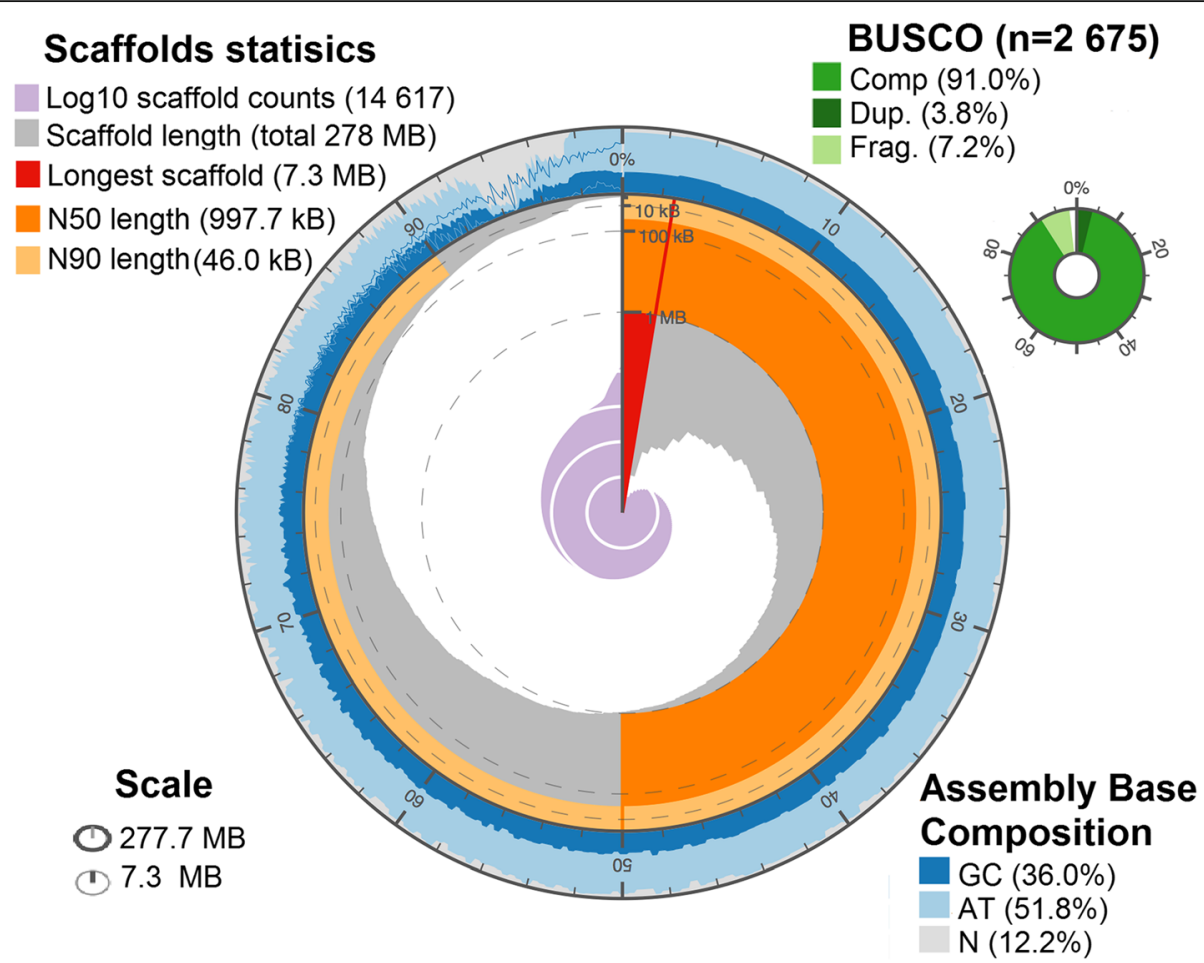

Fig. 1 De novo genome assembly of $F$. exsecta genome, summarized by the following metrics: a) Overall assembly length, b) Number of scaffolds/contigs, c) Length of the longest scaffold/contig, d) Scaffold/contig N50 and N90, e) Percentage GCs and percentage Ns, f) BUSCO completeness, g) Scaffold/contig length/count distribution

We used Basic Local Alignment Search Tool (BLAST) and orthology analyses to characterize $F$. exsecta genes. The vast majority $(88 \% ; 12,050)$ of these had the highest BLASTp similarity to genes in other ants. A further $0.4 \%$ had the highest similarity to Apidae, and $0.6 \%$ to Braconidae, Amniota, and Wolbachia (the latter probably due to HGT; see below and Fig. 2). The remaining 3.09\% belong to other taxa not included in Fig. 2 because they had fewer than 20 hits. The remaining genes $(7.91 \%, n=1080)$ lacked clear sequence similarity [cutoff for BLASTx $\mathrm{E}<10^{-3}$ ] to known protein sequences or protein domains. Some of these may represent erroneous gene predictions [46], however 994 of them are $\geq 1000 \mathrm{bp}$, and include an open reading frame > 300 amino acids long, which is unlikely to occur by chance. Importantly, although only a single pooled transcriptome library, prepared from different developmental life stage samples, was available for $F$. exsecta, 235 of the genes are expressed (FPKM $\geq 1$ ) [42]. It is thus likely that a high proportion of the 1080 genes $(7.91 \%)$ are taxonomically restricted genes, unique to the $F$. exsecta lineage. Information on taxonomically restricted genes in the other published Formicinae genomes (Camponotus floridanus, Lasius niger, Formica selysi) is limited, but the initial publication of the genome of Solenopsis invicta (Myrmicinae) reported 18\%

Table 1 Genome assembly statistics for F. exsecta and its Wolbachia endosymbiont

\begin{tabular}{lll}
\hline Genome Assembly Stats & Formica exsecta Genome & FE Wolbachia endosymbiont Genome \\
\hline Total length & $277,719,392(277 \mathrm{MB})$ & $3,096,460$ (3.09 MB) \\
Total contigs & 14,617 & 69 \\
Contigs (>= $1000 \mathrm{bp})$ & $3136(98.24 \%$ genome $)$ & $68(99.97 \%$ genome $)$ \\
Contigs (>= 50,000 bp) & $545(89.59 \%$ genome $)$ & $22(75.48 \%$ genome $)$ \\
N50: & $997,654 \mathrm{bp}$ & $104,167 \mathrm{bp}$ \\
N75: & $318,356 \mathrm{bp}$ & $54,296 \mathrm{bp}$ \\
L50: & 73 & 11 \\
L75: & 185 & 22 \\
GC (\%) & 36.00 & 35.13 \\
\hline
\end{tabular}


Table 2 BUSCO quality metrics for the genome assemblies of F. exsecta and the Wolbachia endosymbiont of F. exsecta (wFex)

\begin{tabular}{llllllll}
\hline & \multicolumn{3}{l}{ Formica exsecta Genome } & & & wFex Genome \\
\cline { 2 - 3 } BUSCO metric & Eukaryota & Insecta & Arthropoda & Hymenoptera & & Bacteria & Proteobacteria \\
\hline Complete & $299(98.7 \%)$ & $1634(98.5 \%)$ & $2549(95.29 \%)$ & $4249(96.2 \%)$ & $107(72.30 \%)$ & $158(71.49 \%)$ \\
Complete and single copy & $283(93.4 \%)$ & $1572(94.8 \%)$ & $2446(91.44 \%)$ & $4151(94.0 \%)$ & $35(23.65 \%)$ & $55(24.88)$ \\
Complete and duplicated & $16(5.3 \%)$ & $62(3.7 \%)$ & $103(3.86 \%)$ & $98(2.2 \%)$ & $72(48.65 \%)$ & $103(46.60 \%)$ \\
Fragmented & $1(0.3 \%)$ & $15(0.9 \%)$ & $195(7.29 \%)$ & $123(2.8 \%)$ & $9(6.08 \%)$ & $11(4.97 \%)$ \\
Missing & $3(1.0 \%)$ & $9(0.6 \%)$ & $34(1.27 \%)$ & $43(1.0 \%)$ & $32(21.62 \%)$ & $52(23.52 \%)$ \\
Total & $303(100 \%)$ & $1658(100 \%)$ & $2675(100 \%)$ & $4415(100 \%)$ & $148(100 \%)$ & $221(100 \%)$ \\
\hline
\end{tabular}

taxonomically restricted genes [43], and a study comparing genomes of 7 ant species found an average of 1715 species-specific genes [47], indicating that high proportions of taxon-specific genes can be present also in other ant.

The genes of $F$. exsecta $(n=13,637)$ were grouped into 7727 orthologous clusters (Fig. 3). Comparative analysis of the $F$. exsecta genes with the closely related species
Camponotus floridanus and Lasius niger, and the more distantly related Solenopsis invicta and Cerapachys biroi revealed that 4685 out of 7727 orthologous clusters are shared between all five species. In addition, we found 102 gene clusters that were exclusive to three Formicinae genomes ( $F$. exsecta, Camponotus floridanus and Lasius niger; Additional file 2: Table S2). Such genes are

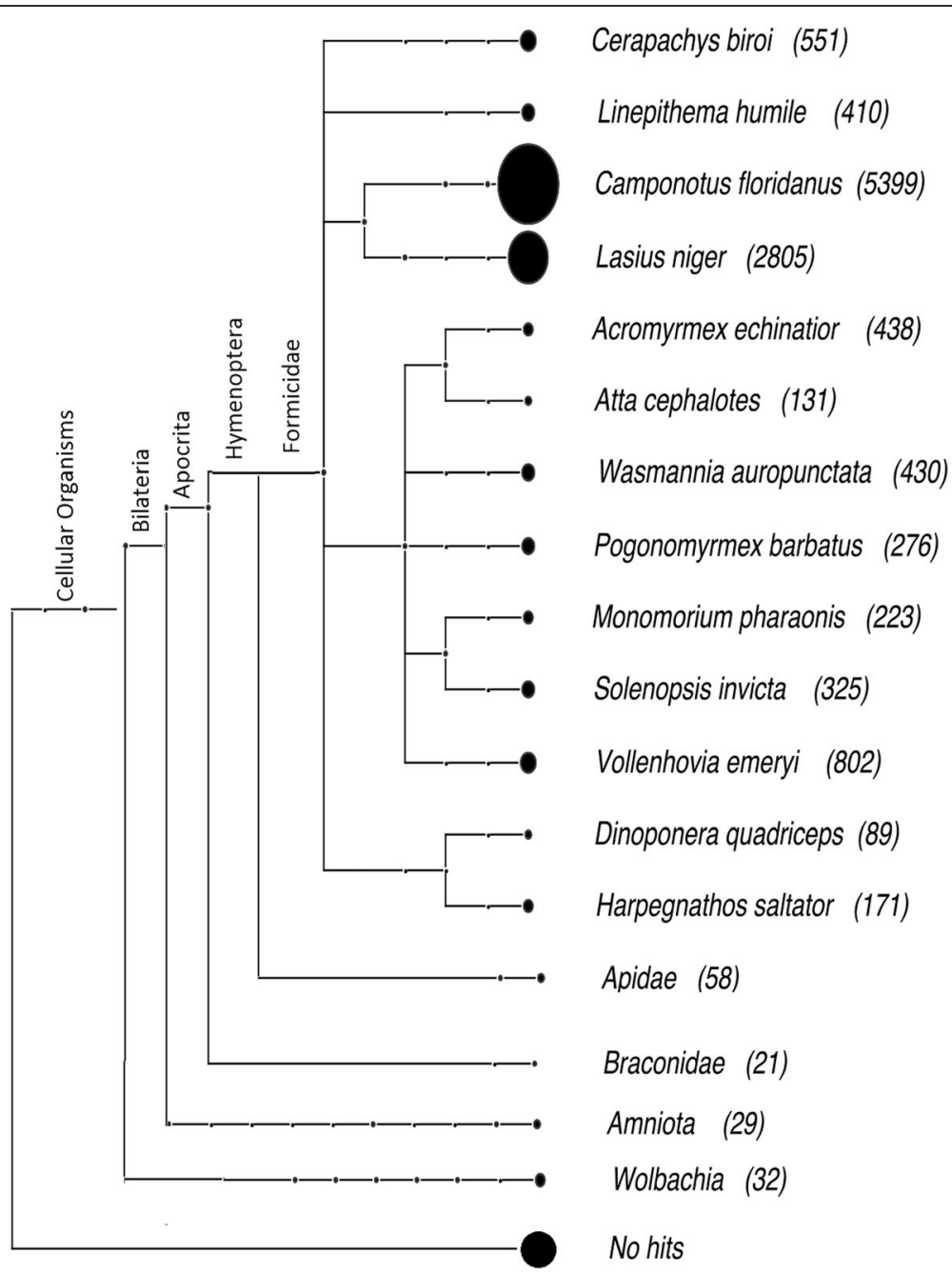

Fig. 2 Taxonomic distribution of the best BLASTp hits of $F$. exsecta proteins to the non-redundant (nr) protein database $\left(E<10^{-5}\right)$ 

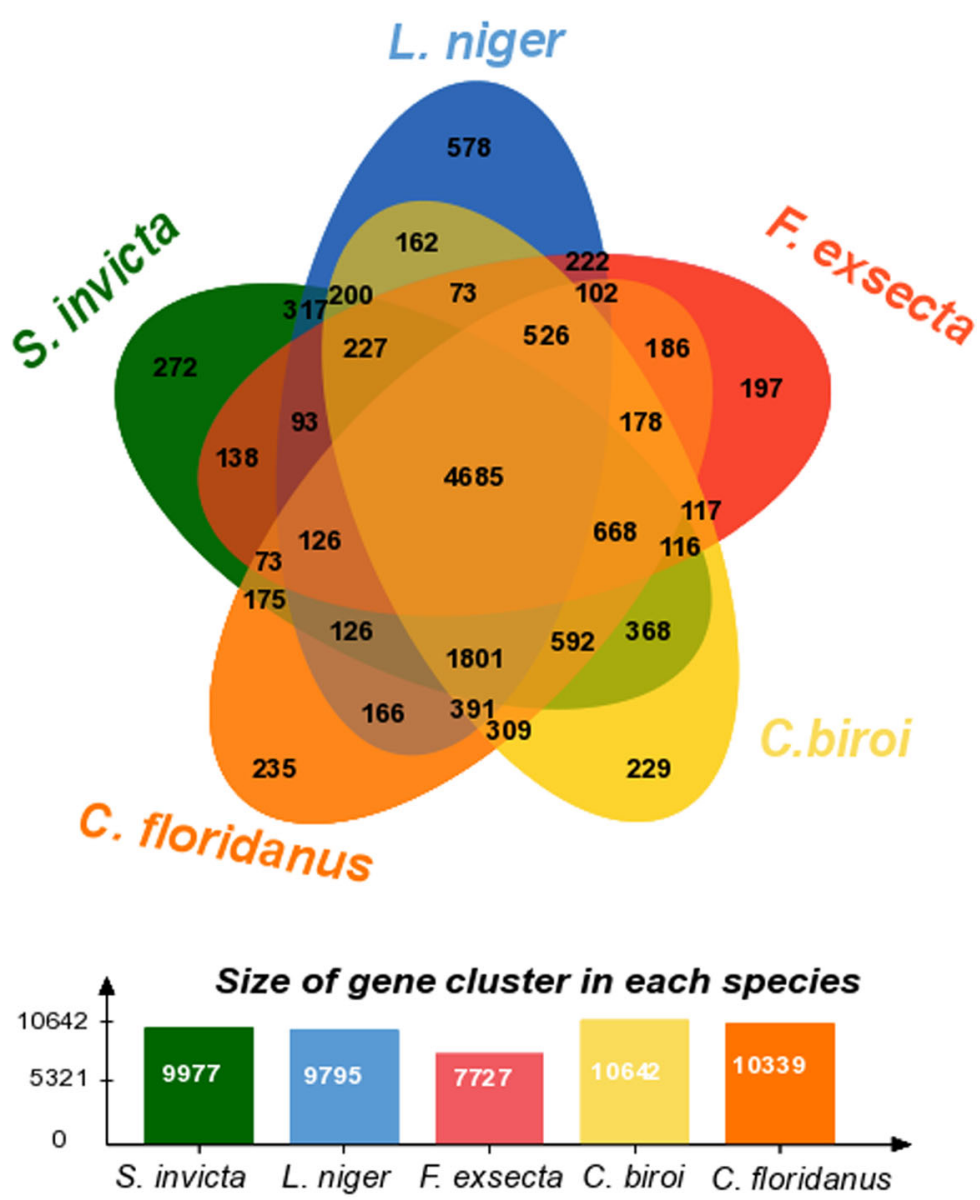

Number of gene clusters : specific (1) or shared by 2, 3,4,5 species

\begin{tabular}{|c|c|c|c|c|}
\hline 4685 & 3348 & 1944 & 2160 & 1511 \\
\hline 5 & 4 & 3 & 2 & 1
\end{tabular}

Fig. 3 Venn diagram showing the distribution of gene families (orthologous clusters) among five ant species including three closely related members of the subfamily Formicinae (F. exsecta, Camponotus floridanus, Lasius niger), and two distinctly related ants (Solenopsis invicta and Cerapachys biroi)

important candidates that could be involved in the evolution of this subfamily. Many of the genes in these clusters had no detectable relation to existing genes outside the Formicinae; those that did, included GO annotations such as glycerate kinase, transferase activity, deoxyribonucleoside diphosphate metabolic process.

Interestingly, 633 of the $F$. exsecta-specific genes could be grouped into 197 ortholog clusters of 2 or more genes (Additional file 3: Table S3), suggesting not only newly evolved genes, but also potential gene duplication and subfunctionalisation. Previous comparative genome studies have indicated that $10-20 \%$ of genes lack recognizable homologs in other species in every taxonomic group so far studied [48-51]. Our lower percentage of orphan genes could be due to our hierarchical approach to annotation, the wide range of databases used, and the large amounts of ant genomic data generated over the past years [52].

\section{Genes with signatures of evolution under positive selection}

We performed analyses to detect genes with signatures of positive selection in $F$. exsecta. First, selection analysis (dN/ dS ratio estimations) on 3157 single-copy genes shared between the five core ant species (without paralogous genes), revealed that 500 genes have signatures of positive selection in the lineage leading to $F$. exsecta. These include genes involved in fatty acid metabolism, lipid catabolism, and chitin metabolism (Additional file 4: Table S4). Interestingly, previous studies on ants, bees, and flies also provide evidence for positive selection on genes in similar functional categories as 
in our study [53]. For example, genes involved in biological functions such as carbohydrate metabolic processes, lipid metabolic processes, cytoskeleton organization, cell surface receptor signaling pathways, and RNA processing were overrepresented in the enrichment analysis, and such genes were also previously reported as positively selected genes in ants, bees, and flies [53, 54].

To perform a similar analysis on a larger number of genes, we used a second approach based on pairwise comparisons between $F$. exsecta and Camponotus floridanus. Out of 5148 one-to-one- orthologs, 29 showed $\mathrm{dN} / \mathrm{dS}>1 \quad(P<0.005$; Additional file 5: Table S5). Although some of these putative genes could be artefactual or non-coding, they all include an open reading frame of $>100$ amino acids. Five (17\%) out of 29 genes are likely linked to transposon activity as they are transposase-like or have EpsG domains. Among the other genes, only a few are annotated: the Icarapin-like protein is a venom gene, and such genes have been shown to be under positive selection in wasps [55]. Perhaps more surprisingly we found a high $\mathrm{dN} / \mathrm{dS}$ ratio for the Homeobox protein gene orthopedia, which is involved in early embryonic development [56]. The orthopedia gene plays a significant role in the development of the nervous system in both fruit flies (Drosophila sp.), and mice (Mus musculus) [57], and has both novel and conserved roles in other taxa [58]. The diversification of this gene could contribute to the evolution of the nervous system in these ants. The modalities of the putative faster evolution of this gene will become clearer as further transcriptomic data becomes available from $F$. execta, and genome sequence becomes available from other Formicinae.

\section{Repetitive elements}

Repetitive elements comprised $15.88 \%$ (44.10 Mb) of the $F$. exsecta assembly. This proportion is similar to that found in other ants (16.5-31.5\% [45]. This is probably an underestimate because (i) genomic regions that cannot be assembled are enriched with such repeats, (ii) multiple copies of a repetitive element are often collapsed into a single copy during genome assembly, and (iii) only a portion of repetitive elements in $F$. exsecta will have similarity to sequences in standard repeat databases. Overall, $3.18 \%(8.8 \mathrm{Mb})$ of the assembly was composed of simple repeats, whereas $12.73 \%$ (35.34 Mb) comprised interspersed repeats, most of which (53.73\%) could not be classified. Among those that could be classified, 10,542 retro element fragments represented 2.74\% of the genome, and 53,438 DNA transposons represented $4.23 \%$ of the genome. The $F$. exsecta genome contains copies of the piggyBac transposon (23 in total, and 7 within intact ORFs). Higher numbers (234) of piggyBac transposons have been found in Camponotus floridanus, yet only 6 of these were found within ORFs [59].

\section{The Wolbachia endosymbiont genome of $F$. exsecta}

The assembly of the "Wolbachia endosymbiont genome of $F$. exsecta" (henceforth $w \mathrm{Fex}$ ), was $3.09 \mathrm{Mb}$ long, encompassing 69 scaffolds with a N50 scaffold length of 104,167 nt, and a GC content of 35.13\% (Table 1; GenBank, Bioproject: PRJNA436771). This assembly of $w$ Fex shows extensive nucleotide similarity with the complete genome of the Wolbachia endosymbiont of Drosophila simulans, wRi (GenBank ID: NC_012416.1), and the Wolbachia endosymbiont of Dactylopius coccus, strain $w$ DacA (GenBank ID: NZ_LSYX00000000) (Additional file 6: Figure S1). We determined that 549 genes are present as a single copy in the Wolbachia genomes most closely related to $w$ Fex ([60] see below); 537 $(99.6 \%)$ out of these 539 core genes are present in the $w$ Fex genome, suggesting high completeness.

However, the $w$ Fex genome is considerably larger (3.09 $\mathrm{Mb})$ than the Wolbachia genomes reported previously (range: 0.95 to $1.66 \mathrm{Mb}$ ) [61], and includes a greater number of open reading frames (1796 ORFs) than other published Wolbachia genomes [range: 644 to 1275 genes]. Formica exsecta is known to carry more than one Wolbachia strain [36], thus these patterns could be due to the presence of multiple endosymbiont strains. Three lines of evidence provide support for this. First, 212 genes $(11.80 \%)$, which are present as single-copy genes in the $w \mathrm{Mel}, w \mathrm{Ri}$, and $w \mathrm{Dac}$ genomes [62-64], are present twice in our assembly (Additional file 7: Table S6). Conversely, the Wolbachia strains are apparently very closely related and thus have highly similar genomic regions which were collapsed during assembly, which may explain why only $11.8 \%$ of the single copy genes differ. Second, $92(12 \%)$ of the 775 genes present as single copies in $w F$ Fex, included genetic variation within our sample. This also included the cytochrome c oxidase subunit I $(\operatorname{Cox} A)$, where no such variation is normally expected. Finally, we found 2 copies of the MLST genes (ftsZ, hcpA and gatB), and of the CI inducing genes cifA and cifB [65], on different scaffolds. Thus it is highly likely that the assemby of $w$ Fex comprises multiple strains. Despite extensive attempts, we were unable to disentangle the two or more Wolbachia strains, probably because differences in synteny between the strains cannot be resolved using short-read sequence data. Similar assembly artifacts, due to multiple Wolbachia strains, have also been reported by other studies [64].

To determine how $w$ Fex is related to other Wolbachia, we used Bayesian phylogenetic analysis based on 12 single copy genes (Additional file 8: Table S7) from the 25 available Wolbachia genomes from the NCBI database. The analysis revealed three distinct monophyletic clades, all with posterior probabilities $>0.9$. Each of these clades represent one super group of Wolbachia (Fig. 4). Of these three supergroups, two have been found only in arthropods (super groups A and B), whereas the third super group is 
found only in filarial nematodes (super group C) [17]. In the phylogenetic analysis, $w$ Fex clustered with the Wolbachia strains within super group A. This is consistent with earlier studies on Wolbachia in ants, which also found supergroup A in the majority of the infected ants [31]. The closest relative of $w$ Fex was the strain $w$ DacA which infects the scale insect, Dactylopius coccus. Our phylogeny is also consistent with the recent published phylogeny of Wolbachia [66].

Given that $w$ Fex affiliates with the supergroup A in our phylogenetic analysis, we investigated the extent to which its gene content aligned with that of other Wolbachia genomes in the same supergroup. The taxonomic distribution of the best BLASTp (protein blast) hits of the $w$ Fex protein to the nonredundant protein $(\mathrm{nr})$ database had highest similarity to $w$ Dac protein sequences. This supports the inference made from the phylogeny, that $w \mathrm{Fex}$ is more closely related to $w$ Dac than to other Wolbachia strains. We found that 525 genes were shared across all strains in this supergroup $\mathrm{A}$, including $w \mathrm{Fex}$ (Fig. 5). About $20 \%$ of these genes had no match to known proteins, whereas the remaining genes matched a wide range of predicted functions $[60,63]$. We also found strain-specific genes ( $w$ Fex - 50 genes, $w \mathrm{Mel}$ - 4 genes, $w$ Ri - 3 genes, $w$ Dac - 9 genes). The $w$ Fex-specific genes included inferred annotations including Ankyrin repeat protein, ATP synthase, and chromosome partition protein (Additional file 9: Table S8). These strain-specific genes can provide an interesting snapshot of the evolutionary dynamics of a species. For example, ankyrin repeat proteins are involved in numerous functional processes, and have been suggested to play an important role in host-symbiont interactions [67]. Comparative analyses suggest that they may be involved in host communication and reproductive phenotypes [68].

To explore differences in gene content between CI-inducing, and non-CI-inducing strains of Wolbachia, homologous genes in six CI-inducing, and three non-CI-inducing strains were aligned, and compared [60]. The non-CI-inducing Wolbachia strains (range: 644-805 genes) contained fewer genes than the CI-inducing ones (range: 911-1275 genes). The CI-inducing strains shared 84 genes, not found in the non-CI-inducing strains. We found $80(95.23 \%)$ of these 84 genes in $w$ Fex (Additional file 10: Figure S2), as well as the genes cifA and cifB, which are involved in the $\mathrm{CI}$ mechanism (Additional file 11: Figure S3). Both copies of genes appear to be functional as their lengths are $100 \%$ in comparison to similar gene sequences available in NCBI database. Together this supports the assumption that $w \mathrm{Fex}$ is a CI-inducing Wolbachia strain, but we warrant that genomic information is unable to conclusively demonstrate this.
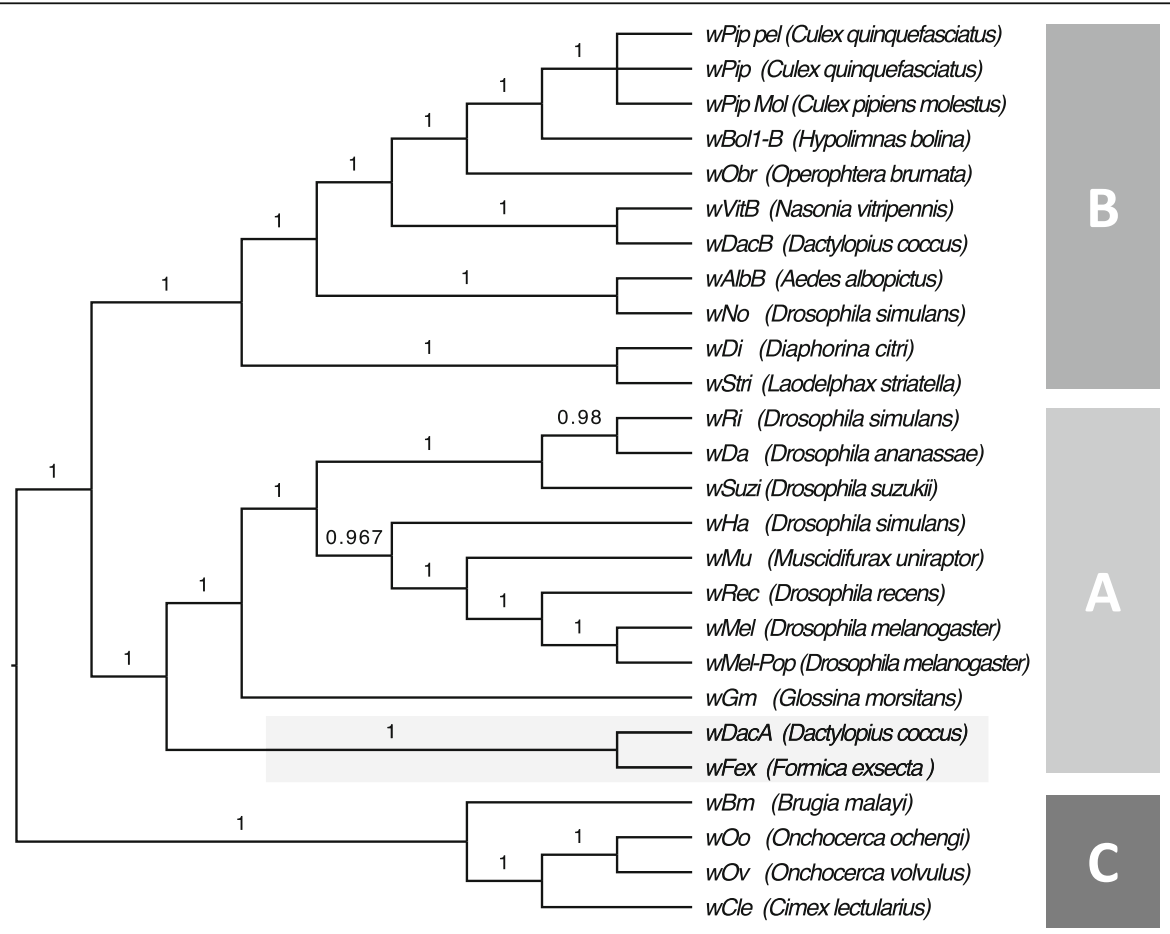

1.0

Fig. 4 Phylogeny of the Wolbachia supergroups $\mathbf{a}, \mathbf{b}$, and $\mathbf{c}$ strains with the newly assembled wFex genome. The phylogenetic reconstructions are based on individual analyses of 12 single copy core genes of 25 Wolbachia strains. The support values on the branch labels indicate Bayesian posterior probabilities. The letters a-c indicate the separate supergroups 

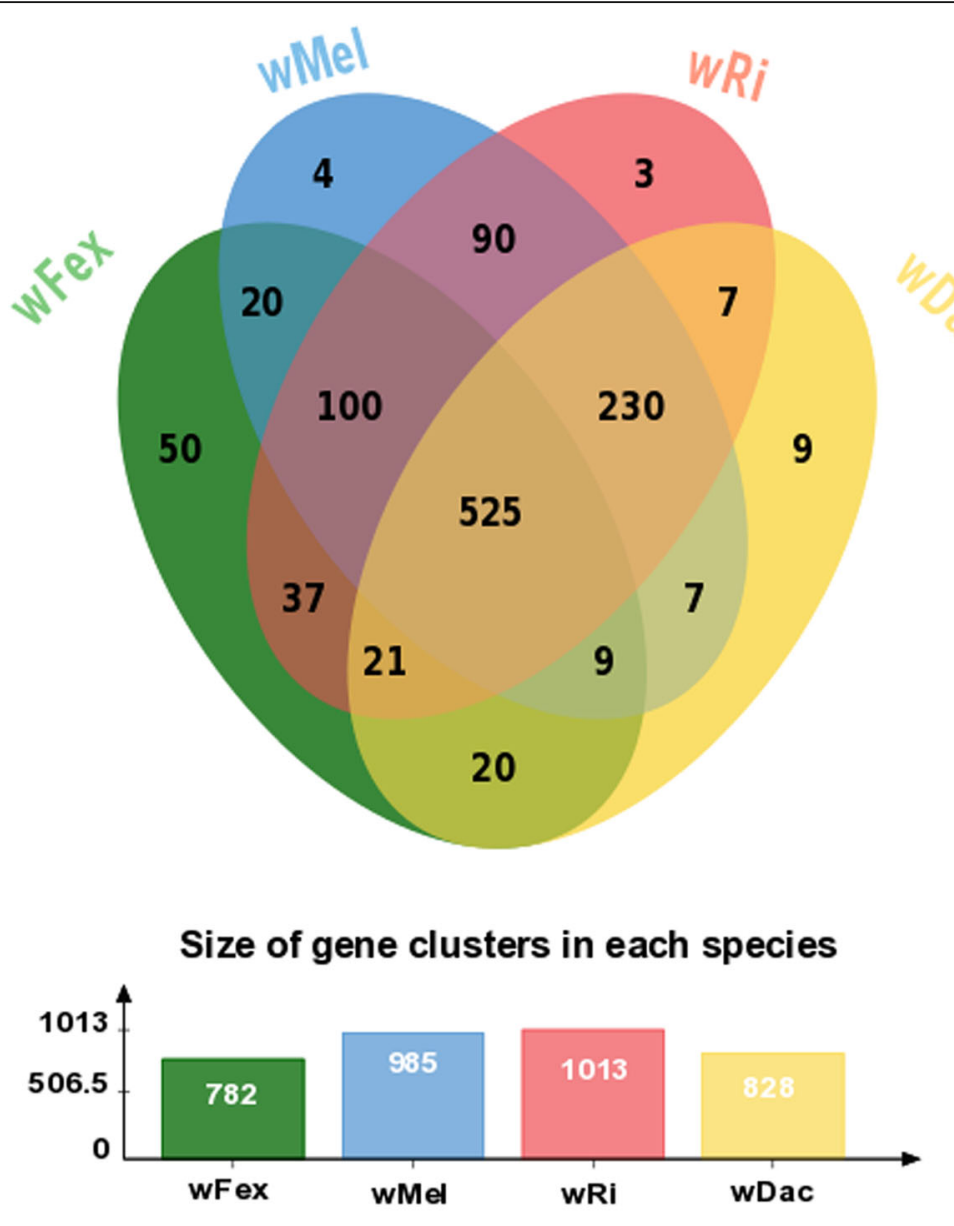

Number of gene clusters: specific (1) or shared by 2, 3, 4 species

\begin{tabular}{c|c|c|c|}
\hline 525 & 360 & 181 & \\
\hline 4 & 3 & 2 & $1(66)$
\end{tabular}

Fig. 5 Venn diagram displaying the overlap in orthologous genes among four Wolbachia species including the newly assembled wFex strain and the wDac, wRi, wMel strains reported previously

Horizontal gene transfers, and functional novelty Intracellular symbionts can contribute new genes or fragments of genes to the host genome via horizontal gene transfer [7, 17, 69]. We found evidence for ancestral horizontal transfer of cytoplasmic Wolbachia to the host $F$. exsecta in five scaffolds (scaffold83, scaffold233, scaffold574, scaffold707, scaffold741) (chromosomal Wolbachia). The four largest transfers are 13 to $47 \mathrm{~kb}$ long, and include $83 \mathrm{pu}$ tative functional protein coding genes, whereas the fifth and smallest insertion $(475 \mathrm{bp})$ lacks protein coding genes, other than a degenerate Wolbachia transposase. This transposase is present in 7 out of 29 published Wolbachia genomes. The chromosomal Wolbachia showed high similarity to the cytoplasmic Wolbachia (88.2-99.2\%) (Additional file 12: Figure S4). Of the 83 putative functional protein coding genes from chromosomal Wolbachia, we found 38 genes in cytoplasmic Wolbachia using BLAST; but the other 45 genes were missing. It is difficult for us to validate with certainty whether these 45 genes were absent in $w$ Fex due to the fragmented assembly of the cytoplasmic Wolbachia (wFex). Our analysis shows that similar transfer events of this homologous fragment apparently also have occurred from cytoplasmic Wolbachia to the genomes of the ants Vollenhovia emeryi (gene: LOC105557741), and Cardiocondyla obscurior (scaffolds scf7180001101632 and scf7180001108526), as well as the microfilarial nematode Brugia pahangi, the Arizona spittle bug Clastoptera arizona, and the parasitoid wasp Diachasma alloeum.

One-third of invertebrate genomes are thought to contain recent Wolbachia gene insertions, ranging in size 
from short segments $(<600 \mathrm{bp})$, to nearly the entire genome $[17,25]$. Most of these transferred fragments contained transposable elements, as well as some other functional genes from the Wolbachia genome. The presumptive HGT events from Wolbachia to $F$. exsecta are located in or near regions with transposases. Our BLAST results suggest that four of the insert regions had Wolbachia transposases, whereas one insert region has a transposase of ant origin. Whether the presence of such transposases close to HGT sites facilitates insertions is unknown. Interestingly, the putative functional protein-coding genes of Wolbachia inserted in the $F$. exsecta genome are similar to the genes reported in similar HGTs events in other insect genomes (eg: ABC transporter, Ankyrin repeat containing protein (Table 3) $[70,71]$. This could indicate that some HGT events are either more likely to occur or to be retained for reasons that could be neutral or adaptive to the host or to the endosymbiont. The transcriptome of $F$. exsecta shows that at least 6 out of the 83 genes from the Wolbachia HGT regions are transcribed, but with a low FPKM values (range 0.04 to 1.6). These low level transcription trait often observed in bacteria-eukaryote HGTs $[7,25,29]$.

\section{Conclusions}

Here we present the first draft genome of the ant $F$. exsecta, and its Wolbachia endosymbiont. This is the first report of a Wolbachia genome from ants, and provides insights into its phylogenetic position. We further identified multiple HGT events from Wolbachia to $F$. exsecta. Some of these have also occurred in parallel in several other insect genomes, highlighting the extent of HGTs in eukaryotes. We expect that the F. exsecta genome will be a valuable resource in understanding the molecular basis of the evolution of social organization in ants: Recent genomic comparisons between Formica selysi and Solenopsis invicta have shown convergent evolution of a social chromosome, that underpins social organisation in these ants [72]. Additional comparison of these genomic regions with $F$. exsecta could provide valuable insights on the evolution of genomic architectures underlying social organization.

\section{Methods}

\section{Sample collection and genome sequencing}

Our study population of $F$. exsecta, located on the Hanko peninsula, Southwestern Finland, has been monitored since 1994, and data on demography, genetic structure, and ecology are available [73-76]. Based on genetic data on colony kin structure most $(97 \%)$ of the approximately 200 colonies are known to have a single reproductive queen, mated to one or more (usually two) males [73-76]. We selected one single-queen colony from our study population on the island Furuskär (F162), and collected 200 adult males from this colony. We used males because in Hymenoptera these arise through arrhenotoky [77] and are haploid [78], meaning that a pool of males together are representative of the diploid genome of their mother. DNA extraction was done from testis, which contains sperm cells and organ tissue, to avoid contamination by gut microbiota. We used a Qiagen Genomic-tip 20/G extraction kit according to the manufacturer's protocol. For Illumina sequencing we constructed three small insert paired-end libraries (insert sizes of $200 \mathrm{bp}, 500 \mathrm{bp}, 800 \mathrm{bp}$ ), and four mate pair (large insert paired-end) libraries (insert sizes of $2 \mathrm{~kb}, 5 \mathrm{~kb}, 10 \mathrm{~kb}$ and $20 \mathrm{~kb}$ ), each containing DNA from 15 to 50 pooled males. Libraries were prepared using protocols recommended by the manufacturers. Sequencing was done at the Beijing Genomics Institute (BGI) using HiSeq2000, which produced a total of 99.97 GB of raw data (Table 4).

\section{Genome assembly}

We assembled the $F$. exsecta genome using SOAPdenovo2 version 2.04 [79] in three main steps. First, a de Bruijn graph was constructed using short length insert library reads with default parameters ( $k$-mer value of $45)$, to construct the contigs. The initial contig assembly contained 104,190 contigs with an N50 size of 22,328 bp, and total length of $276.23 \mathrm{Mb}$ of sequence, at an average depth of coverage of $47.37 \times$. Second, all individual reads were realigned onto the contigs. Because reads are paired, they can aid with scaffolding: The number of reads supporting the adjacency of each pair of contigs was calculated and weighted by the ratio between consistent and conflicting paired ends. Scaffolds were constructed in a stepwise manner using libraries of increasing sizes from $500 \mathrm{bp}$ insert size paired-end reads up to mate-pair of $5 \mathrm{~kb}$ insert size. Eighty thousand four hundred seventy-three contigs could not be placed in scaffolds. These are highly similar repetitive sequences, since the cd-hit-est tool [80] showed that $43 \%$ of these contigs clustered together at $80 \%$ of the sequence length. Third, sequencing gaps in the scaffolds were closed with the two mate-pair libraries (Insert size $10 \mathrm{~kb}$ and $20 \mathrm{~kb}$ ). Overall, these steps produced an initial assembly with an N50 scaffold length of $949,634 \mathrm{bp}$, and a total length of $289,843,734$ bp with each scaffold longer than $200 \mathrm{bp}$.

We used blobology v1.0 [81] to generate taxon-annotated GC-coverage (TAGC) plots of scaffolds in the genome assembly, which can help to identify bacterial contamination (Additional file 13: Figure S5). The scaffolds for the TAGC plot were successfully annotated to the taxonomic order based on the best BLAST match to the NCBI nt database [82]. This analysis revealed that 74 scaffolds matched the endosymbiotic bacterium 


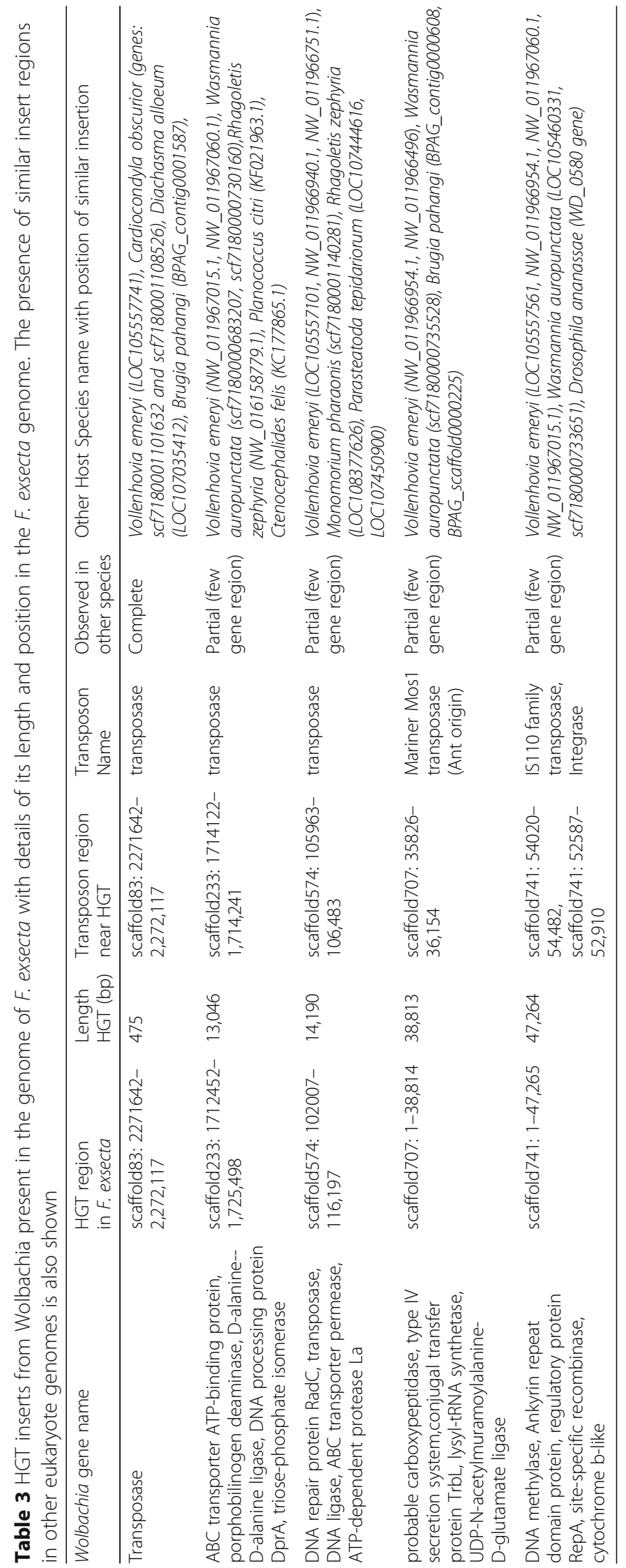


Table 4 Summary statistics for the raw sequencing data, before and after filtering reads. "Coverage depth" was calculated based on the estimated assembled genome size (300 Mb)

\begin{tabular}{llllll}
\hline $\begin{array}{l}\text { Insert } \\
\text { Size }\end{array}$ & $\begin{array}{l}\text { Pair } \\
\text { reads } \\
\text { Length } \\
(\mathrm{bp})\end{array}$ & Raw & Sequence coverage $(\mathrm{X})$ & After Filter \\
\cline { 5 - 6 } & $100 \mathrm{bp}$ & 22.68 & 45.36 & Total Data $(\mathrm{G})$ & Sequence coverage $(\mathrm{X})$ \\
\hline $170 \mathrm{bp}$ & $100 \mathrm{bp}$ & 8.54 & 17.08 & 20.96 & 41.93 \\
$500 \mathrm{bp}$ & $100 \mathrm{bp}$ & 8.84 & 17.69 & 7.34 & 14.69 \\
$800 \mathrm{bp}$ & $100 \mathrm{bp}$ & 13.23 & 26.46 & 5.14 & 10.29 \\
$2 \mathrm{~kb}$ & $100 \mathrm{bp}$ & 14.51 & 29.02 & 7.05 & 14.10 \\
$5 \mathrm{~kb}$ & $100 \mathrm{bp}$ & 11.77 & 23.53 & 4.74 & 9.49 \\
$10 \mathrm{~kb}$ & $100 \mathrm{bp}$ & 20.40 & 40.81 & 5.51 & 11.02 \\
$20 \mathrm{~kb}$ & - & 99.97 & 199.95 & 2.91 & 5.81 \\
Total & & & & 53.66 & 107.32 \\
\hline
\end{tabular}

Wolbachia. Sixty-nine of these scaffolds were removed as we concluded that they are part of the Wolbachia genome (see analysis below), but five contigs were retained in the final assembly for $F$. exsecta as they contained both Wolbachia and ant sequences. Following this curation, the final draft genome assembly was 277.7 $\mathrm{Mb}$ long with an N50 value of $997,654 \mathrm{bp}$ and $36 \%$ Guanine-cytosine (GC) content (Table 1).

\section{Genome assembly of Wolbachia}

All 25 published Wolbachia genomes were obtained from the NCBI database [82]. We aligned the 74 scaffolds from the initial F. exsecta assembly that matched with Wolbachia against these genomes using MUMmer 3.23 [83], and inspected the alignments manually. Sixty-nine of the 74 scaffolds matched completely to Wolbachia genomic regions. These 69 scaffolds represented $3.09 \mathrm{Mb}$ total, with a N50 value of $104,167 \mathrm{bp}$, and referred to as "the Wolbachia endosymbiont genome of $F$. exsecta" ( $w \mathrm{Fex}$ ).

The remaining five scaffolds each contained several interspersed fragments with similarity to Wolbachia genomes, whereas other parts of these scaffolds had high similarity to genomes of ants [84]. Furthermore, the sequencing coverage of these scaffolds was similar to the F. exsecta scaffolds, rather than to the Wolbachia scaffolds. Finally, detailed inspection of these scaffolds in a genome browser showed no change in sequencing depth where we identify the interspersed fragments with similarity to Wolbachia, which would be expected for erroneous chimeric assembly [85]. These data thus suggest that fragments of Wolbachia were horizontally transferred to the $F$. exsecta genome. To corroborate these results with independent approaches, we re-assembled the raw sequencing data with two additional independent algorithms that we expect would make different types of assembly errors than SOAPdenovo. The first software, Velvet version 1.2.09 [86], is also based on a de Bruijn graph; the second, SGA version 0.10.5 [87] is based on a string graph. Both resulting assemblies confirmed the patterns we had seen, and validate the idea that the five SOAPdenovo scaffolds containing sequence with similarity to both ants, and Wolbachia represent horizontal gene transfers from Wolbachia to F. exsecta. To ensure the robustness of the assembly of 69 scaffolds of the Wolbachia genome ( $w \mathrm{Fex})$, we re-assembled the $w$ Fex genome by excluding the reads which mapped to the HGT region of $F$. exsecta genome. Thus, the chromosomal Wolbachia should not affect the assembly of the cytoplasmic Wolbachia.

We further compared the sequences of the horizontally transferred fragments in the five SOAPdenovo scaffolds against the NCBI (nr/nt) database [82], using BLAST 2.2.27 [88] to determine whether these fragments may have also undergone horizontal gene transfer in other arthropod genomes. We performed analogous searches on ant genomes present in the NCBI, and the Fourmidable databases [84]. When a positive match with any other ant or arthropod genomes was found, the exact location of the insertion was determined, and compared with that of F. exsecta. Finally, the five scaffolds were also compared to the F. exsecta transcriptome [42], using BLASTn 2.2.27, to assess similarity with expressed sequences.

\section{Quantitative assessment of genome assemblies}

The quality of the genome assembly is crucial, as it defines the quality of all subsequent analyses that are based on the genome sequences. We explored multiple assembly options (data not shown), and used two methods to assess assembly quality and robustness in order to select the highest quality assembly. First, we evaluated genome contiguity (number and length of contigs) using Quast 3.2 [89] to assess whether our newly assembled draft genome is comparable to published ant genomes [52] based on assembly statistics (N50, N90). Second, we used core gene content-based quality assessment using CEGMA 2.4 [90] to ascertain that the 248 most highly 
conserved eukaryotic proteins are present in our genome assembly. We also compared genes present in our genome assembly to single-copy orthologs across four lineage-specific sets (Eukaryota (303 genes), Insecta (1658 genes), Arthropoda (2675 genes), and Hymenoptera (4415 genes)) using the BUSCO 1.1 [91]. In addition, we compared the $F$. exsecta genome with 13 other ant genomes, Camponotus floridanus, Atta cephalotes, Acromyrmex echinatior, Cardiocondyla obscurior, Cerapachys biroi, Lasius niger, Linepithema humile, Monomorium pharaonis, Pogonomyrmex barbatus, Vollenhovia emeryi, Wasmannia auropunctata, Harpegnathos saltator, and Solenopsis invicta [84], using BUSCO. We report BUSCO quality metrics for the $F$. exsecta genome (Table 2).

The quality of the Wolbachia endosymbiont genome was quantified with a similar approach, where we used BUSCO to examine the presence of Universal Single-Copy Orthologs of the Bacteria (148 genes), and the Proteobacteria (221 genes) lineages (Table 2). We also used BUSCO to compare the $w$ Fex genome with four other Wolbachia genomes, including the Wolbachia endosymbionts of Drosophila simulans ( $w \mathrm{Ri}$ and $w \mathrm{No}$ ), Culex quinquefasciatus (wPip), and Drosophila melanogaster (wMel).

\section{Gene prediction}

We combined several publicly available data sets and computational gene prediction tools to establish an Official Gene Set (OGS) for the $F$. exsecta genome. First, we used the MAKER version 2.28 pipeline [92, 93], to derive consensus gene models from Augustus version 3.1.0 [94], SNAP version 2016-07-28 [95], and Exonerate version 2.2.0 [96]. For this MAKER prediction we used as input datasets the $F$. exsecta transcriptome (ESTs) (Bioproject ID: PRJNA213662, [42]), and the proteomes of all available ant species (Uniprot download on 20-04-2015). The longest protein at each genomic locus was retained, resulting in a set of 23,517 gene models. Because samples may have different sets of transcripts, owing to different biological conditions or developmental stages [42], we additionally made a separate transcript-spliced assembly using RNA sequences generated from separate libraries for different life stages [42], using the Tophat version 2.1.0 [97], and Cufflinks version 2.2.1 [98]. The assemblies from the different samples were then merged using cuffmerge [98]. We further obtained separate Augustus version 3.1.0 [94], and Glimmer version 3.02 [99] gene models with default settings (Augustus: $\quad-$-species $=$ fly - -genemodel $=$ partial, --strand = both, Glimmer: $+\mathrm{f},+\mathrm{s},-\mathrm{g} 60$ ). The gene sets and gene models from MAKER and from other programs were then merged. Redundancy was removed by favoring for each transcript the longest prediction starting with a methionine. If several transcripts had the same length we retained the one which had the best support from the cufflinks transcript assembly. This redundancy removal resulted in a final set of 13,637 protein coding gene models (final OGS), which contained 33,121 transcripts.

\section{Genome annotation}

We analyzed the complete official gene sets (OGS) of $F$. exsecta to identify sequence and functional similarity by comparing with different sequence databases using BLAST. By using a ribosomal database, we were able to annotate both the large (LSU), and the small (SSU) subunit ribosomal RNAs. The remaining gene sequences were used for retrieving functional information from other databases (SwissProt, Pfam, PROSITE, and COG). Gene sequences were considered to be coding if they had a strong unique hit to the SwissProt protein database [100, 101], or appeared to be orthologs of known predicted protein-coding genes from ant species based on TrEMBL (Translation of EMBL nucleotide sequence database). We also assigned putative metabolic pathways, functional classes, enzyme classes, GeneOntology terms, and locus names with the AutoFact tool [102]. To further improve annotation, and for assigning biological function (e.g. gene expression, metabolic pathways), we also did orthologous searches by comparing with other Hymenoptera sequences [84]. To quantify variation in the numbers of protein family members, we performed Pfam (version 24.0) [103] and PROSITE profile [104] analyses on proteins obtained from the $F$. exsecta gene set. Our final annotation included gene sequences with retrieved protein-related names, functional domains, and expression in other organisms along with enzyme commission (EC) numbers, pathway information, Cluster of Orthologous Groups (COG), functional classes, and Gene Ontology terms.

\section{Orthology and evolutionary rates}

Comparative genome-wide analysis of orthologous genes was performed with OrthoVenn [105] to compare the predicted $F$. exsecta protein sequences with those of four other ant species, Camponotus floridanus, Lasius niger, Solenopsis invicta, and Cerapachys biroi, all of which were downloaded from their respective public NCBI repositories. The predicted proteins of $F$. exsecta and the other four species were uploaded into the OrthoVenn web server for identification and comparison of orthologous clusters [105]. Following clustering, orthAgogue was used for the identification of putative orthology and inparalogy relationships. To deduce the putative function of each ortholog, the first protein sequence from each cluster was searched against the non-redundant protein database UniProt using BLASTp 2.2.27. Pairwise sequence similarities among protein sequences were determined for all species with a BLASTp 2.2.27 (E-value cut-off of $10^{-5}$, and an inflation value of 1.5 for MCL). Finally, an interactive Venn diagram, summary counts, 
and functional summaries of clusters shared between species were visualized using OrthoVenn.

To identify genes under positive or relaxed purifying selection in $F$. exsecta, we estimated the rates of non-synonymous to synonymous changes for core orthologous genes (3156) from five ant species (F. exsecta, Camponotus floridanus, Lasius niger, Solenopsis invicta, and Cerapachys biroi). For this we only included orthologous groups with one ortholog for each species (no paralogous genes were included) in the analysis. We extracted coding and protein sequences for 3156 orthologous groups from the respective public NCBI repositories for the species included. We then aligned all protein sequences using Clustal Omega [106], and then converted them to nucleotide sequences with PAL2NAL version 14. [107]. We then ran CODEML version 4.9e [107], using the branch site model with $F$. exsecta as foreground branch, and the other five ant species as background lineages. The Bayes empirical method (Yang et al. 2005) was used to estimate the posterior probabilities, which were then used to identify sites under selection. We additionally estimated pairwise $\mathrm{dN} / \mathrm{dS}$ ratios for orthologous genes (5148 genes) between Camponotus floridanus and $F$. exsecta in CODEML.

We also ran an orthology analysis between the proteins from three Wolbachia species published previously ( $w \mathrm{Ri}, w \mathrm{Dac}, w \mathrm{Mel}$; [62-64]), to find similarities with the predicted protein sets of the newly assembled $w$ Fex genome. Orthologs were identified using OrthoVenn (E-value cut-off of $10^{-5}$ and inflation value 1.5). In addition, we analyzed the paralogous genes within the $w$ Fex genome, to help understand the increased genome size in comparison to other Wolbachia genomes.

\section{Discovery and annotation of transposable elements}

We used RepeatMasker version 4.0.7 [108], and the TransposonPSI version 08-22-2010 [109] to detect repetitive elements in the genome. To retrieve and mask repetitive elements, we downloaded files from the Repbase and Dfam databases, and aligned each of them with the $F$. exsecta genome sequences as query sequences. Positive alignments were regarded as repetitive regions and extracted for further analysis. To identify genome sequence region homology to proteins encoded by different families of transposable elements, we used the TransposonPSI analysis tool. This tool uses PSI-BLAST, with a collection of retro-transposon ORF homology profiles to identify statistically significant alignments.

\section{Wolbachia phylogeny}

We analysed the phylogeny of Wolbachia in MrBayes v3.2.6 $\times 64$ [110], using a concatenated sequences of 12 genes which were present as single copy in $w$ Fex genome. For this analysis, each gene was considered as a different partition, and the most fitting nucleotide substitution model was chosen for each gene, using the bayesian information criterion (BIC) in the program jMODELTEST (Posada, 2008). The partitioned dataset was run for 200,000 generations, sampling at every 100th generation with each partition unlinked for the substitution parameters. Convergence of the runs was confirmed by checking that the potential scale reduction factor was $\sim 1.0$ for all model parameters, and by ensuring that an average split frequency of standard deviations $<0.01$ was reached [110]. The first $25 \%$ of the trees were discarded as burn-in, and the remaining trees were used to create a $50 \%$ majority-rule consensus tree, and to estimate the posterior probabilities. To check for consistency of the phylogeny, Markov chain Monte Carlo (MCMC) runs were repeated to get a similar 50\% majority-rule consensus tree with high posterior probabilities. The phylogenetic tree generated was visualized using Figtree v1.4.2 [111].

\section{Additional files}

Additional file 1: Table S1. Comparison of assembly statistics of the $F$. exsecta genome and 13 other published ant genomes. (XLSX 11 kb)

Additional file 2: Table S2. List of genes specific to the Formicinae as identified by OrthoVenn. (XLSX $20 \mathrm{~kb}$ )

Additional file 3: Table S3. List of species-specific genes in F. exsecta, as identified by OrthoVenn. (XLSX 24 kb)

Additional file 4: Table S4. List of $F$. exsecta genes under positive or relaxed purifying selection ( $\mathrm{dN} / \mathrm{dS}$ ratios $>1$ ) in comparison to five other ant species (Camponotus floridanus, Lasius niger, Solenopsis invicta and Cerapachys biroi) (XLSX $115 \mathrm{~kb}$ )

Additional file 5: Table S5. List of $F$. exsecta genes showing $d N / d S$ ratios $>1$ in pairwise comparison to Camponotus floridanus. (XLSX 11 kb)

Additional file 6: Figure S1. Visualization of genome coverage of $w F e x$ against the Wolbachia endosymbiont of Drosophila simulans (wRi) genome, and Dactylopius coccus (wDac), using the alignment software circoletto. (PDF $2210 \mathrm{~kb}$ )

Additional file 7: Table S6. List of genes with paralogs in the $w F e x$ genome, which are present as single copies in the wMel, wRi, wDac genomes. (XLSX $27 \mathrm{~kb}$ )

Additional file 8: Table S7. List of conserved Wolbachia genes used for phylogenetic analysis. (XLSX $14 \mathrm{~kb}$ )

Additional file 9: Table S8. List of species-specific genes in WFex genome, as identified by OrthoVenn. (XLSX $15 \mathrm{~kb}$ )

Additional file 10: Figure S2. Venn diagram displaying the overlap in orthologous genes across Cl-inducing and mutualist Wolbachia species. (PDF $98 \mathrm{~kb}$ )

Additional file 11: Figure S3. Schematic representation of cifA and cifB gene locations on the WFex genome assembly. (PDF 27 kb)

Additional file 12: Figure S4. Visualization of sequence similarity between chromosomal Wolbachia and cytoplasmic Wolbachia, using the alignment software circoletto. (PDF $777 \mathrm{~kb}$ )

Additional file 13: Figure S5. TAGC plot of $F$. exsecta, and its Wolbachia endosymbiont. The TAGC plots were taxonomically annotated, and the contigs with best similarity to Arthropoda and Proteobacteria are highlighted in color. (PDF $121 \mathrm{~kb}$ )

\section{Abbreviations}

BP: BasePair; BUSCO: Benchmarking Universal Single-Copy Orthologs; CEGMA: Core Eukaryotic Genes Mapping Approach; COG: Cluster of Orthologous Groups; EC: enzyme commission (EC); ESTs: Expressed Sequence Tag; FPKM: Fragments Per Kilobase Million; GAGA: Global Ant Genome Alliance; HGT: Horizontal Gene Transfer; LSU rRNA: large subunit ribosomal ribonucleic acid; MB: MegaBases; MCMC: Markov chain Monte Carlo; 
OGS: Official Gene Set; ORF: Open Reading Frame; SGA: String Graph Assembler; SSU rRNA: Small subunit ribosomal ribonucleic acid; TEs: Transposable Elements; TrEMBL: Translation of EMBL nucleotide sequence database

\section{Acknowledgements}

The authors thank Kalevi Trontti, Jenni Paviala, and Minttu Ahjos for help with the laboratory work. Pekka Pamilo, Jonna Kulmuni for useful comments on an earlier draft of the manuscript.

\section{Funding}

This work was funded by the Academy of Finland (Centre of Excellence in Biological Interactions, grants no. 252411 and 284666 to L. Sundström), the University of Helsinki (to L. Sundström), the Biotechnology and Biological Sciences Research Council (grant no. BB/K004204/1 to Yannick Wurm), and the Natural Environment Research Council (grant NE/L00626X/1 to Yannick Wurm). The funding provided by the Academy of Finland, and the University of Helsinki covered both the salaries of $L S, A N, K D$, and $H J$ during the entire study, as well as the costs of sequencing, and annotation. The funding by BBSRC and NERC covered research visits between the laboratories, as well as running expenses, including of bioinformatics analyses in the UK.

\section{Availability of data and materials}

The raw Illumina sequences of paired-end and mate-pair libraries are deposited on the National Center for Biotechnology Information (NCBI) under the bio-project number PRJNA393850, with the accession numbers SAMN07344805-SAMN07344811. The assembled genome sequence of $F$. exsecta is deposited on GenBank with the accession number NPMM00000000. Similarly, the draft genome assembly of $w F e x$ is deposited under the project number PRJNA436771.

\section{Authors' contributions}

$\mathrm{KD}$ conceived and designed the FE genome sequencing, carried out the read assembly, genome annotations, performed the bioinformatics analyses, and wrote the manuscript draft, AN conducted the bioinformatic and phylogenetic analysis associated with Wolbachia genome, and wrote the manuscript draft, HJ structured and wrote the initial manuscript draft, YW conducted and supervised the bioinformatics analyses, and wrote the final drafts of the manuscript, LS initiated and planned the project, acquired the funding, and wrote the final draft of the manuscript. All authors read and approved the final manuscript.

\section{Ethics approval and consent to participate}

No specific permits are required for collection of insects according to Finnish laws.

\section{Consent for publication}

Not applicable.

\section{Competing interests}

The authors declare that they have no competing interests.

\section{Publisher's Note}

Springer Nature remains neutral with regard to jurisdictional claims in published maps and institutional affiliations.

\begin{abstract}
Author details
'Organismal and Evolutionary Biology Research Programme, Faculty of Biological and environmental sciences, University of Helsinki, P.O. Box 65, $\mathrm{Fl}-00014$ Helsinki, Finland. ${ }^{2}$ Organismal Biology Department, School of Biological and Chemical Sciences, Queen Mary University of London, Mile End Road, London E1 4NS, UK. ${ }^{3}$ Tvärminne Zoological Station, University of Helsinki, J.A. Palménin tie 260, Fl-10900 Hanko, Finland.
\end{abstract}

Received: 17 November 2018 Accepted: 2 April 2019 Published online: 16 April 2019

\section{References}

1. González J, Karasov TL, Messer PW, Petrov DA. Genome-wide patterns of adaptation to temperate environments associated with transposable elements in Drosophila. PLoS Genet. 2010;6:e1000905. https://doi.org/10. 1371/journal.pgen.1000905.

2. Casacuberta E, González J. The impact of transposable elements in environmental adaptation. Mol Ecol. 2013;22:1503-17. https://doi.org/10. 1111/mec.12170.

3. Rostant WG, Wedell N, Hosken DJ. Transposable Elements and Insecticide Resistance. Adv Genet. 2012:169-201. https://doi.org/10.1016/B978-0-12394394-1.00002-X

4. Wybouw N, Pauchet $Y$, Heckel DG, Van Leeuwen T. Horizontal gene transfer contributes to the evolution of arthropod herbivory. Genome Biol Evol. 2016;8:1785-801. https://doi.org/10.1093/gbe/evw119.

5. Schönknecht G, Weber APM, Lercher MJ. Horizontal gene acquisitions by eukaryotes as drivers of adaptive evolution. Bioessays. 2014;36:9-20. https:// doi.org/10.1002/bies.201300095.

6. Boto L. Horizontal gene transfer in the acquisition of novel traits by metazoans. Proc R Soc B Biol Sci. 2014;281:20132450. https://doi.org/10. 1098/rspb.2013.2450.

7. Dunning Hotopp JC. Horizontal gene transfer between bacteria and animals. Trends Genet. 2011;27:157-63. https://doi.org/10.1016/j.tig.2011.01.005.

8. Matveeva TV, Lutova LA. Horizontal gene transfer from Agrobacterium to plants. Front Plant Sci. 2014;5:326. https://doi.org/10.3389/fpls.2014.00326.

9. Yue J, Hu X, Sun H, Yang Y, Huang J. Widespread impact of horizontal gene transfer on plant colonization of land. Nat Commun. 2012;3:1152. https://doi.org/10.1038/ncomms2148.

10. Rolland T, Neuvéglise C, Sacerdot C, Dujon B. Insertion of horizontally transferred genes within conserved syntenic regions of yeast genomes. PLoS One. 2009;4:e6515. https://doi.org/10.1371/journal.pone.0006515.

11. Bruto M, Prigent-Combaret C, Luis P, Moënne-Loccoz Y, Muller D. Frequent, independent transfers of a catabolic gene from bacteria to contrasted filamentous eukaryotes. Proc Biol Sci. 2014;281:20140848. https://doi.org/10. 1098/rspb.2014.0848.

12. Fitzpatrick DA. Horizontal gene transfer in fungi. FEMS Microbiol Lett. 2012; 329:1-8. https://doi.org/10.1111/j.1574-6968.2011.02465.x.

13. Werren JH. Wolbachia run amok. Proc Natl Acad Sci. 1997;94:11154-5. https://doi.org/10.1073/pnas.94.21.11154.

14. Ferree PM, Frydman HM, Li JM, Cao J, Wieschaus E, Sullivan W. Wolbachia utilizes host microtubules and dynein for anterior localization in the Drosophila oocyte. PLoS Pathog. 2005;1:e14. https://doi.org/10.1371/journal.ppat.0010014.

15. de Oliveira CD, Gonçalves DS, Baton LA, Shimabukuro PHF, Carvalho FD, Moreira LA. Broader prevalence of Wolbachia in insects including potential human disease vectors. Bull Entomol Res. 2015;105:305-15. https://doi.org/10.1017/S0007485315000085.

16. Sazama EJ, Bosch MJ, Shouldis CS, Ouellette SP, Wesner JS. Incidence of Wolbachia in aquatic insects. Ecol Evol. 2017;7:1165-9. https://doi.org/10. 1002/ece3.2742

17. Werren JH, Baldo L, Clark ME. Wolbachia: master manipulators of invertebrate biology. Nat Rev Microbiol. 2008;6:741-51. https://doi.org/10. 1038/nrmicro1969.

18. Goodacre SL, Martin OY, Thomas CFG, Hewitt GM. Wolbachia and other endosymbiont infections in spiders. Mol Ecol. 2006;15:517-27. https://doi. org/10.1111/j.1365-294X.2005.02802.x.

19. Cordaux R, Michel-Salzat A, Bouchon D. Wolbachia infection in crustaceans: novel hosts and potential routes for horizontal transmission. J Evol Biol. 2001;14:237-43. https://doi.org/10.1046/j.1420-9101.2001.00279.x.

20. Fenn K, Conlon C, Jones M, Quail MA, Holroyd NE, Parkhill J, et al. Phylogenetic relationships of the Wolbachia of nematodes and arthropods. PLoS Pathog. 2006;2:e94. https://doi.org/10.1371/journal.ppat.0020094.

21. Moya A, Peretó J, Gil R, Latorre A. Learning how to live together: genomic insights into prokaryote-animal symbioses. Nat Rev Genet. 2008;9:218-29. https://doi.org/10.1038/nrg2319.

22. Klasson L, Kambris Z, Cook PE, Walker T, Sinkins SP. Horizontal gene transfer between Wolbachia and the mosquito Aedes aegypti. BMC Genomics. 2009; 10:33. https://doi.org/10.1186/1471-2164-10-33.

23. Woolfit M, Iturbe-Ormaetxe I, McGraw EA, O'Neill SL. An ancient horizontal gene transfer between mosquito and the endosymbiotic bacterium Wolbachia pipientis. Mol Biol Evol. 2009;26:367-74. https:/doi.org/10.1093/ molbev/msn253.

24. Aikawa T, Anbutsu H, Nikoh N, Kikuchi T, Shibata F, Fukatsu T. Longicorn beetle that vectors pinewood nematode carries many Wolbachia genes on an autosome. Proc R Soc B Biol Sci. 2009;276:3791-8. https://doi.org/10. 1098/rspb.2009.1022. 
25. Hotopp JCD, Clark ME, Oliveira DCSG, Foster JM, Fischer P, Torres MCM, et al. Widespread lateral gene transfer from intracellular Bacteria to multicellular eukaryotes. Science (80- ). 2007;317:1753-1756. doi:https://doi. org/10.1126/science.1142490.

26. Nikoh N, McCutcheon JP, Kudo T, Miyagishima S, Moran NA, Nakabachi A. Bacterial genes in the aphid genome: absence of functional gene transfer from Buchnera to its host. PLoS Genet. 2010;6:e1000827. https://doi.org/10 1371/journal.pgen.1000827.

27. Nikoh N, Nakabachi A. Aphids acquired symbiotic genes via lateral gene transfer. BMC Biol. 2009;7:12. https://doi.org/10.1186/1741-7007-7-12.

28. Kondo N, Nikoh N, ljichi N, Shimada M, Fukatsu T. Genome fragment of Wolbachia endosymbiont transferred to $X$ chromosome of host insect. Proc Natl Acad Sci. 2002;99:14280-5. https://doi.org/10.1073/pnas.222228199.

29. Nikoh N, Tanaka K, Shibata F, Kondo N, Hizume M, Shimada M, et al. Wolbachia genome integrated in an insect chromosome: evolution and fate of laterally transferred endosymbiont genes. Genome Res. 2008;18:272-80. https://doi.org/10.1101/gr.7144908.

30. Husnik F, McCutcheon JP. Functional horizontal gene transfer from bacteria to eukaryotes. Nat Rev Microbiol. 2017;16:67-79. https//doi.org/10.1038/nrmicro.2017.137.

31. Werren $J H$, Windsor DM. Wolbachia infection frequencies in insects: evidence of a global equilibrium? Proc R Soc Lond Ser B Biol Sci. 2000;267: 1277-85. https://doi.org/10.1098/rspb.2000.1139.

32. Keller L, Liautard C, Reuter M, Brown WD, Sundström L, Chapuisat M. Sex ratio and Wolbachia infection in the ant Formica exsecta. Heredity (Edinb). 2001:87:227-33. https://doi.org/10.1046/j.1365-2540.2001.00918.x .

33. Telschow A, Flor M, Kobayashi Y, Hammerstein P, Werren JH. Wolbachiainduced unidirectional cytoplasmic incompatibility and speciation: Mainland-Island model. PLoS One. 2007;2:e701. https://doi.org/10.1371/ journal.pone.0000701.

34. Wenseleers T. Conflict from cell to Colony. Leuven: University of Leuven; 2001.

35. Wenseleers T, Ito F, Van Borm S, Huybrechts R, Volckaert F, Billen J. Widespread occurrence of the microorganism Wolbachia in ants. Proc R Soc Lond Ser B Biol Sci. 1998;265:1447-52. https://doi.org/10.1098/rspb.1998.0456.

36. Reuter M. High levels of multiple Wolbachia infection and recombination in the ant Formica exsecta. Mol Biol Evol. 2003;20:748-53. https://doi.org/10.1093/molbev/msg082.

37. Boomsma JJ, Brady SG, Dunn RR, Gadau J, Heinze J, Keller L, et al. The global ant genomics Alliance (GAGA). Myrmecological News 2017;25 ISSN 1994-4136:61-6.

38. Agosti D, Hauschteck-Jungen E. Polymorphism of males in Formica exsecta Nyl. (Hym:: Formicidae). Insect Soc. 1987;34:280-90. https://doi.org/10.1007/BF02224360.

39. Rosengren M, Rosengren R, Söderlund V. Chromosome numbers in the genus Formica with special reference to the taxonomical position of Formica uralensis Ruzsk. And Formica truncorum Fabr. Hereditas. 2009;92: 321-5. https://doi.org/10.1111/j.1601-5223.1980.tb01715.x.

40. Tsutsui ND, Suarez AV, Spagna JC, Johnston JS. The evolution of genome size in ants. BMC Evol Biol. 2008;8:64. https://doi.org/10.1186/1471-2148-8-64.

41. Henson J, Tischler G, Ning Z. Next-generation sequencing and large genome assemblies. Pharmacogenomics. 2012;13:901-15. https:/doi.org/10.2217/pgs.12.72.

42. Dhaygude K, Trontti K, Paviala J, Morandin C, Wheat C, Sundström L, et al. Transcriptome sequencing reveals high isoform diversity in the ant Formica exsecta. Peer J. 2017;5:e3998. https://doi.org/10.7717/peerj.3998.

43. Wurm Y, Wang J, Riba-Grognuz O, Corona M, Nygaard S, Hunt BG, et al. The genome of the fire ant Solenopsis invicta. Proc Natl Acad Sci U S A. 2011; 108:5679-84. https://doi.org/10.1073/pnas.1009690108.

44. Honeybee Genome Sequencing Consortium. Insights into social insects from the genome of the honeybee Apis mellifera. Nature. 2006;443:931-49. https://doi.org/10.1038/nature05260.

45. Schrader L, Kim JW, Ence D, Zimin A, Klein A, Wyschetzki K, et al. Transposable element islands facilitate adaptation to novel environments in an invasive species. Nat Commun. 2014:5:5495. https://doi.org/10.1038/ncomms6495.

46. Drăgan M-A, Moghul I, Priyam A, Bustos C, Wurm Y. GeneValidator: identify problems with protein-coding gene predictions. Bioinformatics. 2016;32: 1559-61. https://doi.org/10.1093/bioinformatics/btw015.

47. Simola DF, Wissler L, Donahue G, Waterhouse RM, Helmkampf M, Roux J, et al. Social insect genomes exhibit dramatic evolution in gene composition and regulation while preserving regulatory features linked to sociality. Genome Res. 2013;23:1235-47. https://doi.org/10.1101/gr.155408.113.

48. Wilson GA, Feil EJ, Lilley AK, Field D. Large-scale comparative genomic ranking of taxonomically restricted genes (TRGs) in bacterial and archaeal genomes. PLoS One. 2007;2:e324. https://doi.org/10.1371/journal.pone.0000324.
49. Tautz D, Domazet-Lošo T. The evolutionary origin of orphan genes. Nat Rev Genet. 2011;12:692-702. https://doi.org/10.1038/nrg3053.

50. Johnson BR, Tsutsui ND. Taxonomically restricted genes are associated with the evolution of sociality in the honey bee. BMC Genomics. 2011;12:164. https://doi.org/10.1186/1471-2164-12-164.

51. Khalturin K, Hemmrich G, Fraune S, Augustin R, Bosch TCG. More than just orphans: are taxonomically-restricted genes important in evolution? Trends Genet. 2009;25:404-13. https://doi.org/10.1016/j.tig.2009.07.006.

52. Favreau E, Martínez-Ruiz C, Rodrigues Santiago L, Hammond RL, Wurm Y. Genes and genomic processes underpinning the social lives of ants. Curr Opin insect Sci. 2018;25:83-90. https://doi.org/10.1016/j.cois.2017.12.001.

53. Roux J, Privman E, Moretti S, Daub JT, Robinson-Rechavi M, Keller L. Patterns of positive selection in seven ant genomes. Mol Biol Evol. 2014;31:1661-85. https://doi.org/10.1093/molbev/msu141.

54. Viljakainen L, Evans JD, Hasselmann M, Rueppell O, Tingek S, Pamilo P. Rapid evolution of immune proteins in social insects. Mol Biol Evol. 2009;26: 1791-801. https://doi.org/10.1093/molbev/msp086.

55. Werren JH, Richards S, Desjardins CA, Niehuis O, Gadau J, Colbourne $\mathrm{JK}$, et al. Functional and evolutionary insights from the genomes of three parasitoid Nasonia species. Science (80- ). 2010;327:343-348. doi:https://doi.org/10.1126/science.1178028.

56. Mackenzie A, Leeming GL, Jowett AK, Ferguson MW, Sharpe PT. The homeobox gene Hox 7.1 has specific regional and temporal expression patterns during early murine craniofacial embryogenesis, especially tooth development in vivo and in vitro. Development. 1991;111:269-85 http://www.ncbi.nlm.nih.gov/pubmed/1680043.

57. Simeone A, D'Apice MR, Nigro V, Casanova J, Graziani F, Acampora D, et al. Orthopedia, a novel homeobox-containing gene expressed in the developing CNS of both mouse and drosophila. Neuron. 1994;13:83-101. https://doi.org/10.1016/0896-6273(94)90461-8.

58. Nederbragt AJ, te Welscher $\mathrm{P}$, van den Driesche $\mathrm{S}$, van Loon AE, Dictus WJAG. Novel and conserved roles for orthodenticle/ otx and orthopedia/ otp orthologs in the gastropod mollusc Patella vulgata. Dev Genes Evol. 2002;212:330-7. https://doi.org/10.1007/s00427-002-0246-z .

59. Bonasio R, Zhang G, Ye C, Mutti NS, Fang X, Qin N, et al. Genomic comparison of the ants Camponotus floridanus and Harpegnathos saltator. Science (80-) 2010;329:1068-1071. doi:https:/doi.org/10.1126/science.1192428.

60. Lindsey ARI, Werren JH, Richards S, Stouthamer R. Comparative genomics of a parthenogenesis-inducing Wolbachia symbiont. G3\&\#58; Genes|Genomes|Genetics. 2016;6:2113-23. https://doi.org/10.1534/g3.116. 028449 .

61. Sun LV, Foster JM, Tzertzinis G, Ono M, Bandi C, Slatko BE, et al. Determination of Wolbachia genome size by pulsed-field gel electrophoresis. J Bacteriol. 2001; 183:2219-25. https://doi.org/10.1128/JB.183.7.2219-2225.2001.

62. Klasson L, Westberg J, Sapountzis P, Näslund K, Lutnaes Y, Darby AC, et al. The mosaic genome structure of the Wolbachia wRi strain infecting Drosophila simulans. Proc Natl Acad Sci U S A. 2009;106:5725-30. https://doi. org/10.1073/pnas.0810753106.

63. Ellegaard KM, Klasson L, Näslund K, Bourtzis K, Andersson SGE. Comparative genomics of Wolbachia and the bacterial species concept. PLoS Genet. 2013;9:e1003381. https://doi.org/10.1371/journal.pgen.1003381.

64. Ramírez-Puebla ST, Ormeño-Orrillo E, Vera-Ponce de León A, Lozano L, SanchezFlores A, Rosenblueth M, et al. Genomes of Candidatus Wolbachia bourtzisii wDacA and Candidatus Wolbachia pipientis wDacB from the Cochineal Insect Dactylopius coccus (Hemiptera: Dactylopiidae). G3\&amp,\#58; Genes/Genomes|Genetics. 2016;6: 3343-9. doi:https:/doi.org/10.1534/g3.116.031237.

65. LePage DP, Metcalf JA, Bordenstein SR, On J, Perlmutter J, Shropshire JD, Layton EM, Funkhouser-Jones LJ, Beckmann JF, Bordenstein SR. 2017. Prophage WO genes recapitulate and enhance Wolbachia-induced cytoplasmic incompatibility. Nature 543:243-7. https://doi.org/10.1038/ nature21391.

66. Wang X, Xiong X, Cao W, Zhang C, Werren J, Wang X. Genome assembly of the A-group Wolbachia in Nasonia oneida and phylogenomic analysis of Wolbachia strains revealed genome evolution and lateral gene transfer. bioRxiv. 2018;508408. https://doi.org/10.1101/508408.

67. Li J, Mahajan A, Tsai M-D. Ankyrin repeat: a unique motif mediating protein-protein interactions. Biochemistry. 2006;45:15168-78. https:// doi.org/10.1021/bi062188q

68. Voronin DA, Kiseleva E. Functional role of proteins containing ankyrin repeats. Cell and Tissue Biology. 2007:49:989-99. https://doi.org/10.1134/ S1990519X0801001X. 
69. Keeling PJ, Palmer JD. Horizontal gene transfer in eukaryotic evolution. Nat Rev Genet. 2008;9:605-18. https://doi.org/10.1038/nrg2386.

70. Attardo GM, Abila PP, Auma JE, Baumann AA, Benoit JB, Brelsfoard CL, et al. Genome sequence of the tsetse Fly (Glossina morsitans): vector of African trypanosomiasis. Science (80- ). 2014;344:380-386. doi:https://doi.org/10. 1126/science.1249656.

71. Brelsfoard C, Tsiamis G, Falchetto M, Gomulski LM, Telleria E, Alam U, et al. Presence of extensive Wolbachia symbiont insertions discovered in the genome of its host Glossina morsitans morsitans. PLoS Negl Trop Dis. 2014;8: e2728. https://doi.org/10.1371/journal.pntd.0002728.

72. Purcell J, Brelsford A, Wurm Y, Perrin N, Chapuisat M. Convergent genetic architecture underlies social organization in ants. Curr Biol. 2014;24:2728-32. https://doi.org/10.1016/j.cub.2014.09.071.

73. Sundström L, Chapuisat M, Keller L. Conditional manipulation of sex ratios by ant workers: a test of kin selection theory. Science (80- ). 1996;274:993995. doi:https://doi.org/10.1126/science.274.5289.993.

74. Sundström L, Keller L, Chapuisat M. Inbreeding and sex-biased gene flow in the ant Formica exsecta. Evolution. 2003;57:1552-61. https://doi.org/10.1111/ j.0014-3820.2003.tb00363.x.

75. Haag-Liautard C, Vitikainen E, Keller L, Sundström L. Fitness and the level of homozygosity in a social insect. J Evol Biol. 2009;22:134-42. https://doi.org/ 10.1111/j.1420-9101.2008.01635.x.

76. Vitikainen EIK, Haag-Liautard C, Sundström L. Natal dispersal, mating patterns, and inbreeding in the ant Formica exsecta. Am Nat. 2015;186:71627. https://doi.org/10.1086/683799.

77. Normark BB. The evolution of alternative genetic systems in insects. Annu Rev Entomol. 2003:48:397-423. https://doi.org/10.1146/annurev.ento.48.091801.112703.

78. Crozier RH. Hymenoptera. Anim Cytogenet 1975;:95.

79. Xie Y, Wu G, Tang J, Luo R, Patterson J, Liu S, et al. SOAPdenovo-trans: de novo transcriptome assembly with short RNA-Seq reads. Bioinformatics. 2014;30:1660-6. https://doi.org/10.1093/bioinformatics/btu077.

80. Huang Y, Niu B, Gao Y, Fu L, Li W. CD-HIT suite: a web server for clustering and comparing biological sequences. Bioinformatics. 2010;26:680-2. https:// doi.org/10.1093/bioinformatics/bta003.

81. Kumar S, Jones M, Koutsovoulos G, Clarke M, Blaxter M. Blobology: exploring raw genome data for contaminants, symbionts and parasites using taxonannotated GC-coverage plots. Front Genet. 2013;4:237. https://doi.org/10. 3389/fgene.2013.00237.

82. O'Leary NA, Wright MW, Brister JR, Ciufo S, Haddad D, McVeigh R, et al. Reference sequence (RefSeq) database at NCBI: current status, taxonomic expansion, and functional annotation. Nucleic Acids Res. 2016;44:D733-45. https://doi.org/10.1093/nar/gkv1189.

83. Kurtz S, Phillippy A, Delcher AL, Smoot M, Shumway M, Antonescu C, et al. Versatile and open software for comparing large genomes. Genome Biol. 2004;5:R12. https://doi.org/10.1186/gb-2004-5-2-r12.

84. Wurm Y, Uva P, Ricci F, Wang J, Jemielity S, Iseli C, et al. Fourmidable: a database for ant genomics. BMC Genomics. 2009;10:5. https:/doi.org/10.1186/1471-2164-10-5.

85. Lasken RS, Stockwell TB. Mechanism of chimera formation during the multiple displacement amplification reaction. BMC Biotechnol. 2007;7:19. https://doi.org/10.1186/1472-6750-7-19.

86. Zerbino DR, Birney E. Velvet: algorithms for de novo short read assembly using de Bruijn graphs. Genome Res. 2008;18:821-9. https:/doi.org/10.1101/gr.074492.107.

87. Simpson JT, Durbin R. Efficient de novo assembly of large genomes using compressed data structures. Genome Res. 2012;22:549-56. https://doi.org/10.1101/gr.126953.111.

88. Altschul SF, Gish W, Miller W, Myers EW, Lipman DJ. Basic local alignment search tool. J Mol Biol. 1990;215:403-10. https://doi.org/ 10.1016/S0022-2836(05)80360-2.

89. Gurevich A, Saveliev V, Vyahhi N, Tesler G. QUAST: quality assessment tool for genome assemblies. Bioinformatics. 2013;29:1072-5. https://doi.org/10. 1093/bioinformatics/btt086

90. Parra G, Bradnam K, Korf I. CEGMA: a pipeline to accurately annotate core genes in eukaryotic genomes. Bioinformatics. 2007;23:1061-7. https://doi.org/10.1093/bioinformatics/btm071.

91. Simão FA, Waterhouse RM, loannidis P, Kriventseva EV, Zdobnov EM. BUSCO: assessing genome assembly and annotation completeness with single-copy orthologs. Bioinformatics. 2015;31:3210-2. https://doi. org/10.1093/bioinformatics/btv351.

92. Holt C, Yandell M. MAKER2: an annotation pipeline and genome-database management tool for second-generation genome projects. BMC Bioinformatics. 2011;12:491. https://doi.org/10.1186/1471-2105-12-491.
93. Cantarel BL, Korf I, Robb SMC, Parra G, Ross E, Moore B, et al. MAKER: an easy-to-use annotation pipeline designed for emerging model organism genomes. Genome Res. 2008;18:188-96. https://doi.org/10.1101/gr.6743907.

94. Stanke M, Morgenstern B. AUGUSTUS: a web server for gene prediction in eukaryotes that allows user-defined constraints. Nucleic Acids Res. 2005; 33(Web Server):W465-7. https://doi.org/10.1093/nar/gki458.

95. Korf I. Gene finding in novel genomes. BMC Bioinformatics. 2004;5:59. https://doi.org/10.1186/1471-2105-5-59.

96. Slater GSC, Birney E. Automated generation of heuristics for biological sequence comparison. BMC Bioinformatics. 2005;6:31. https://doi.org/10.1186/1471-2105-6-31.

97. Trapnell C, Pachter L, Salzberg SL. TopHat: discovering splice junctions with RNA-Seq. Bioinformatics. 2009;25:1105-11. https://doi.org/10.1093/ bioinformatics/btp120.

98. Trapnell C, Williams BA, Pertea G, Mortazavi A, Kwan G, van Baren MJ, et al. Transcript assembly and quantification by RNA-Seq reveals unannotated transcripts and isoform switching during cell differentiation. Nat Biotechnol. 2010;28:511-5. https://doi.org/10.1038/nbt.1621.

99. Salzberg SL, Delcher AL, Kasif S, White O. Microbial gene identification using interpolated Markov models. Nucleic Acids Res. 1998;26:544-8 http://www.ncbi.nlm.nih.gov/pubmed/9421513.

100. Apweiler R, Bairoch A, Wu CH, Barker WC, Boeckmann B, Ferro S, et al. UniProt: the universal protein knowledgebase. Nucleic Acids Res. 2004; 32(Database issue):D115-9. https://doi.org/10.1093/nar/gkh131.

101. Magrane M, UniProt Consortium. UniProt Knowledgebase: a hub of integrated protein data. Database (Oxford). 2011;2011:bar009. doi: https://doi.org/10.1093/database/bar009.

102. Koski LB, Gray MW, Lang BF, Burger G. AutoFACT: an automatic functional annotation and classification tool. BMC Bioinformatics. 2005;6: 151. https://doi.org/10.1186/1471-2105-6-151.

103. Bateman A. The Pfam protein families database. Nucleic Acids Res. 2004;32: 138D-141. https://doi.org/10.1093/nar/gkh121.

104. Sigrist CJA, Cerutti L, de Castro E, Langendijk-Genevaux PS, Bulliard V, Bairoch $A$, et al. PROSITE, a protein domain database for functional characterization and annotation. Nucleic Acids Res. 2010;38 Database issue: D161-6. https://doi.org/10.1093/nar/gkp885.

105. Wang Y, Coleman-Derr D, Chen G, Gu YQ. OrthoVenn: a web server for genome wide comparison and annotation of orthologous clusters across multiple species. Nucleic Acids Res. 2015;43:W78-84. https:/doi.org/10.1093/nar/gkv487.

106. Sievers F, Higgins DG. Clustal omega, accurate alignment of very large numbers of sequences. Methods Mol Biol. 2014;1079:105-16. https://doi.org/ 10.1007/978-1-62703-646-7_6.

107. Yang Z. PAML: a program package for phylogenetic analysis by maximum likelihood. Bioinformatics. 1997;13:555-6. https://doi.org/10.1093/ bioinformatics/13.5.555.

108. Smit, AFA, Hubley R, Green P. RepeatMasker Open-40. 2015. http:// www.repeatmasker.org.

109. Haas BJ. TransposonPSI; 2011.

110. Ronquist F, Huelsenbeck JP. MrBayes 3: Bayesian phylogenetic inference under mixed models. Bioinformatics. 2003;19:1572-4. https://doi.org/10. 1093/bioinformatics/btg180.

111. Rambaut A. Figtree. 2012. http://tree.bio.ed.ac.uk/software/figtree/.

\section{Ready to submit your research? Choose BMC and benefit from:}

- fast, convenient online submission

- thorough peer review by experienced researchers in your field

- rapid publication on acceptance

- support for research data, including large and complex data types

- gold Open Access which fosters wider collaboration and increased citations

- maximum visibility for your research: over $100 \mathrm{M}$ website views per year

At $\mathrm{BMC}$, research is always in progress.

Learn more biomedcentral.com/submissions 